Journal of Applied Pharmaceutical Science Vol. 5 (11), pp. 055-062, November, 2015

Available online at http://www.japsonline.com

DOI: 10.7324/JAPS.2015.501109

ISSN 2231-3354 (cc) BY-NC-sA

\title{
Chitosan Liposomal microspheres for Ricinoleic acid Encapsulation
}

\author{
Rihab Abd EL Azeem, Ahmed A. Nada*, Ahmed S. Montaser \\ Textile Division/ Pretreatment and Finishing of Cellulose Based Textiles Department, National research centre, Cairo, Egypt.
}

\begin{tabular}{l} 
ARTICLE INFO \\
\hline Article history: \\
Received on: $27 / 06 / 2015$ \\
Revised on: 14/08/2015 \\
Accepted on: 02/09/2015 \\
Available online: $27 / 11 / 2015$ \\
\hline Key words: \\
Ricinoleic acid; anti- \\
inflammatory; encapsulation; \\
microspheres; drug delivery.
\end{tabular}

\begin{abstract}
Ricinoleic acid (RA) is a C18 fatty acid (FA) with a double bond at the C 9 position and a hydroxyl group at the $\mathrm{C}$ (12) position (cis-12-hydroxyoctadeca-9-enoic acid). Recently, RA has been reported as a pro/antiinflammatory and analgesic agent for topical applications to be considered as an alternative to irritant substances that relive pain. However, RA when it is exposed to air, it reacts with the oxygen and decomposes into shortchain aldehydes and ketones. Moreover, pathologically, small amount of anesthetic agent acts on peripheral nerves, producing reversible block in transmission of peripheral nerves impulses. However, larger amounts effect potentially in the central nervous system and may cause cardiac arrest. Accordingly, extended release formulations for local anesthetic agent such as encapsulation, are highly demanded if the drug will be used for long period. In this work, ricinoleic acid, extracted and characterized, was encapsulated into a new matrix made of phospholipid liposomes and chitosan to protect and control RA release. RA release was controlled by crosslinking the matrices using glutaraldehyde. Spectral and morphology analysis are used to characterize the produced microsphere. The cytotoxicity test is considered to examine the final product biocompatibility. The encapsulation efficiency was investigated by UV - Visible spectroscopy.
\end{abstract}

\section{INTRODUCTION}

Ricinoleic acid (RA), a $\mathrm{C}_{18}$, monounsaturated (at $\mathrm{C}_{9-10}$ ), monohydroxylated (at $\mathrm{C}_{12}$ ), and an aliphatic fatty acid, is the main component of the castor oil (Vaisman et al., 2008). The use of RA in medical purposes dates back to the $1500{ }_{\mathrm{BC}}$ when ancient Egyptians chewed the plant seeds with beer to relieve constipation. However, oil has been prescribed to be applied locally for sores and hemorrhoids (Gaginella and Philips, 1975). Recent study results (Gaginella and Philips, 1975; Vieira et al., 2000a and 2000b; Vieira et al., 2001) provide evidence that RA shows a pro- or anti-inflammatory and analgesic action following its topical application, and it represents a useful alternative to irritant substances that relieve pain (Vaisman et al., 2008). Pathologically, small amount of anesthetic agent acts on peripheral nerves, producing reversible block in transmission of peripheral nerves impulses. However, larger amounts effect potentially in the central nervous system and may cause cardiac

\section{* Corresponding Author}

Dr. Ahmed A. Nada, National Research Centre, Pretreatment and Finishing of Cellulose Based Textiles Dept., Egypt. 33 El-Bohoth St., (former El-Tahrir St.,), Dokki, Giza, Egypt. Email: aanada@ncsu.edu arrest (Vaisman et al., 2007). Accordingly, extended release formulations for local anesthetic agent such as encapsulation, are highly demanded if the duration of the drug action is relatively long. Topical application of percutaneous (through unbroken skin) drugs have been developed dramatically via different carries such as; ointments (Raza et al., 2011), creams (Adeyeye et al., 2002; Aramwit and Sangcakul, 2007; Jenning et al., 2000; Miura et al., 2004; Paolino et al., 2002; Sadaf et al., 2006; Zhou et al., 2010), encapsulated beads (Denkbaş and Odabaşi, 2000; Donthidi et al, 2010; Lin and Ayres, 1992; Meyer et al., 1998; Silva et al., 2005), gels (Kumar and Katare, 2005; Sahiner and Singh, 2007; Scartazzini and Luisi, 1988; Shchipunov, 2001; Vintiloiu and Leroux, 2008), and films (Vanin et al., 2005). Several materials either synthetic or natural have been used for producing such delivery matrices (Kumbar et al, 2014). Gelatin (Andreuccetti et al., 2009; Bigi et al., 2001; Bigi et al., 2002; Cao et al., 2007; Cheng et al., 2003; Dong et al., 2006; Gómez-Estaca et al., 2009; Matsuda et al., 1999; Sobral et al., 2001; Tanaka et al., 2005; Vanin et al., 2005; Yakimets et al., 2005), chitosan (Cheng et al., 2003; Gómez-Estaca et al., 2009), cellulose (Adeyeye et al., 2002) and starch derivatives (Donthidi et al., 2010), alginate (Dong et al., 2006; Donthidi et al., 2010; Silva et al., 2005), polyvinyl alcohol 
(Levi et al., 2011), acrylate polymers (Sahiner and Singh, 2007) and many others have been used for performing different matrices for delivery systems. More recently, liposomes, phospholipid vesicles, have been found to be effective as carriers for topical drug administration. Phospholipids molecules spontaneously form bilayer membranes that can be converted to vesicles, namely liposomes. In lipid vesicles, encapsulated drug can be entrapped depending on the drug hydrophobicity (Urano et al., 1988), either on the hydrophilic core or within the hydrophobic bilayer (e.g. fatty acids) (Xi et al., 2006). Liposome physical structure would allow it to pass through lipophilic skin layers and to be trapped within the top layer of the stratum corneum cells. Such behavior is useful for both local treatment and for cosmetic formulations. However, liposomal final product is very soft and easy to collapse (Lee et al., 2009).

In this paper, free ricinoleic fatty acid was isolated from commercial castor oil and new matrix of encapsulation was made of phospholipid liposomes and chitosan. In particular, commercial lecithin was used as a source of phospholipid and RA impregnated beads was prepared using emulsification technique. RA release was controlled by chemical cross-linking and spectral analysis demonstrated the chemical structure of the new matrices.

\section{EXPERIMENTAL}

\section{Materials}

A commercial lecithin from soybean was purchased under trade name Lio. A commercial grade castor oil was generously gifted from Fats and Oils department of Food Industry and Nutrition division at NRC. Chitosan (medium molecular weight), acetone, chloroform, ethylene glycol, glutaraldehyde (GTA), ethyl acetate $(\mathrm{EtOAc})$, potassium hydroxide $(\mathrm{KOH})$, hydrochloric acid $(\mathrm{HCl})$, and deuterated acetone and dimethyl sulfoxide (DMSO) were purchased from Sigma and were used throughout this research without further purification.

\section{Methods}

\section{Preparation of ricinoleic acid from castor oil}

Pure ricinoleic acid (RA) can be obtained by using alkali treatment of commercial castor oil (cold processed) in the presence of alcohol followed by an acidification step to liberate free RA (Salimon et al., 2012).

$250 \mathrm{~g}$ of dried castor oil was transferred to round bottom flask, which has $\mathrm{KOH}$ alcoholic solution (60 g dissolved in 500 $\mathrm{mL}$ of ethyl alcohol) and equipped with water condenser, for refluxing for 1 hour. The product was concentrated under vacuum distillation. The residual was dissolved in $1200 \mathrm{~mL}$ deionized water (the potassium salt of ricinoleic acid is water soluble) and was acidified with conc. $\mathrm{HCl}$ up to $\mathrm{pH}=1$. The free $\mathrm{RA}$ was extracted in ethyl acetate (EtOAc) $(600 \mathrm{~mL})$ and then was dried over night using magnesium sulfate. The oily organic substance was filtered. The solvent (EtOAc) was evaporated using an evaporator at $50{ }^{\circ} \mathrm{C}$.

\section{Preparation of RA chitosan/ liposomal microspheres}

In the current part, chitosan, non-toxic and biopolymer, was used for hardening the liposomal structure as described below. In typical procedure (Figure 1), 2 gm lecithin (locally available source of phospholipid) was placed to $1.5 \mathrm{gm}$ RA dissolved in 50 $\mathrm{mL}$ of chloroform in a $1 \mathrm{~L}$ round-bottomed flask. The dissolved mixture was stirred for $30 \mathrm{~min}$ at room temperature and then concentrated under reduced pressure at $50{ }^{\circ} \mathrm{C}$ for $30 \mathrm{~min}$ till a thin lipid layer formed in the inside-wall of the round flask. Afterwards, $50 \mathrm{~mL}$ of $2 \%$ chitosan solution was added to the flask and stirring was continued for more $2 \mathrm{hrs}$ at $1500 \mathrm{rpm}$ and sonicated for $1 \mathrm{hr}$ (Takahashi et al., 2006). The final product is very stable milky emulsions.

The chitosan-liposomal microspheres with and without RA were produced by dropping the fresh prepared warm emulsion through a syringe needle to a mixture of $75 \mathrm{~mL}$ of commercial oil and $25 \mathrm{~mL}$ acetone under magnetic stirrer for $15 \mathrm{mint}$ at $1000 \mathrm{rpm}$. Small amount of acetone was added to the oil bath and beads were collected and washed several times with acetone (RA dissolves in acetone but lecithin is not) using vortex. Beads were air-dried and stored at $4{ }^{\circ} \mathrm{C}$ for further use. Figure (2) shows the suggested approach of the prepared microspheres.

\section{Preparation of cross-linked microspheres}

Fresh prepared beads were cross-linked with $10 \mathrm{~mL}$ of $0.5 \mathrm{M}$ of GTA solution in phosphate buffered solution (PBS) at $\mathrm{pH}$ 7.4 for different duration (0-2-6 hrs) at ambient temperature with gentle starring (Cheng et al., 2014). The cross-linked beads were washed several times with PBS solution followed by distilled cold water and acetone. The final product was directly subjected to a reduction with an excess of sodium borohydride in buffered solution $(\mathrm{pH}=4)$ to give the corresponding secondary amine. Microspheres were air-dried and stored at $4{ }^{\circ} \mathrm{C}$ for further analysis.

\section{Spectral analysis}

The chemical structure of ricinoleic acid was characterized with FTIR (Vertex 80v (Bruker)), and $\mathrm{H}^{1}$ NMR spectrometer, Avance III 500 (Bruker Biospin), using deuterated chloroform solvent $\left(\mathrm{CDCl}_{3}\right)$.

\section{Morphological characterization}

The microspheres size was examined using an optical microscope (Axio Imager.A1m, Carl Zeiss Jena $\mathrm{GmbH}$ ) equipped with image analyzer (SPOT Insight, Diagnostic instruments inc., Sterling Heights MI, USA; CASCADE II 512, Photometrics, Roper Scientific Inc., Tucson AZ) and a software (Meta Series Software 7.1.1, Molecular Devices). Results were obtained from 5 times measurements.

\section{In vitro drug release experiment}

The release rate of RA from gelatin-based liposomal beads were determined by incubating $50 \mathrm{mg}$ of RA loaded crosslinked beads in $10 \mathrm{~mL}$ PBS (pH 7.4) at $37^{\circ} \mathrm{C}$ in shaking water 


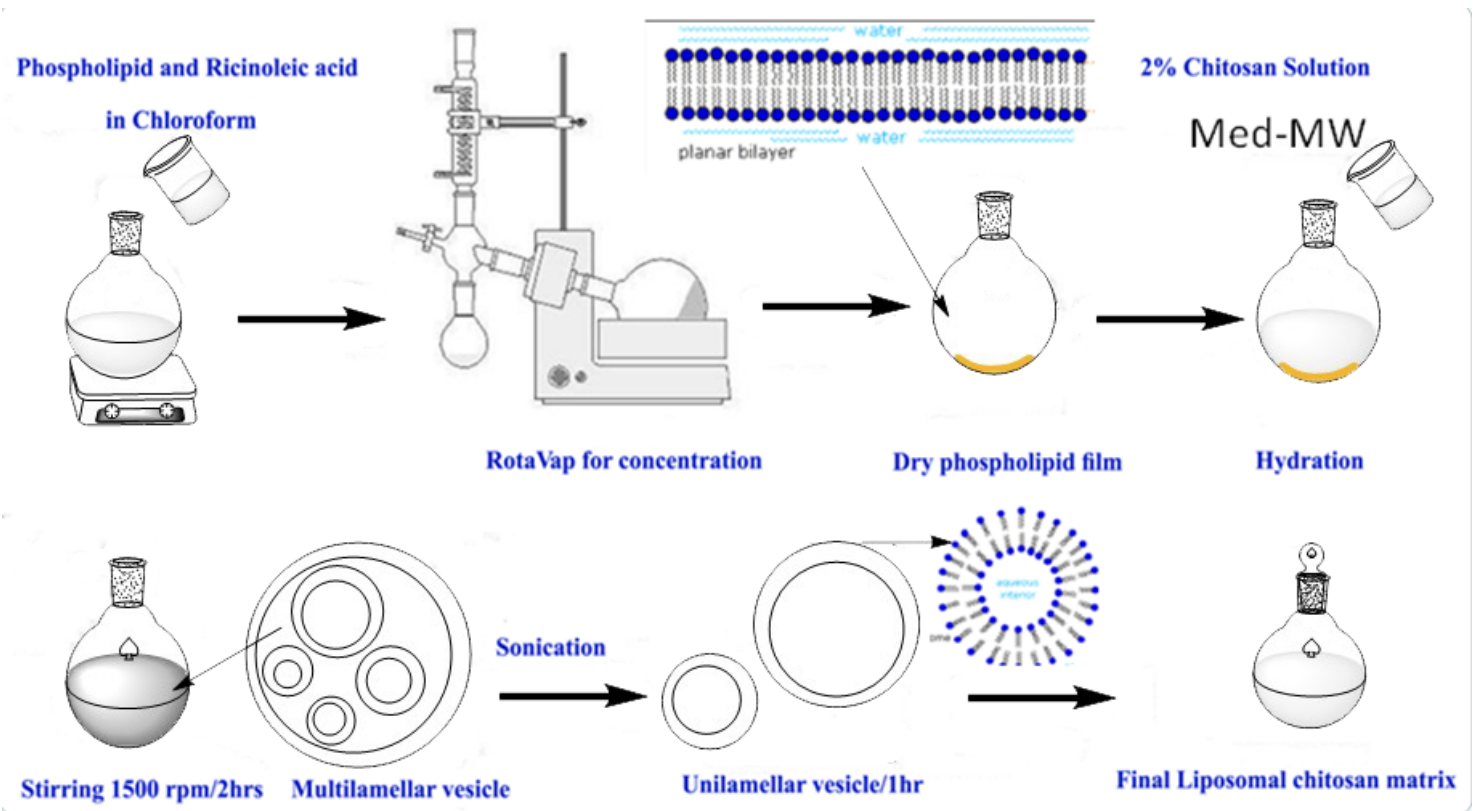

Fig. 1: Schematic diagram of the preparation of RA liposomal/chitosan microspheres..

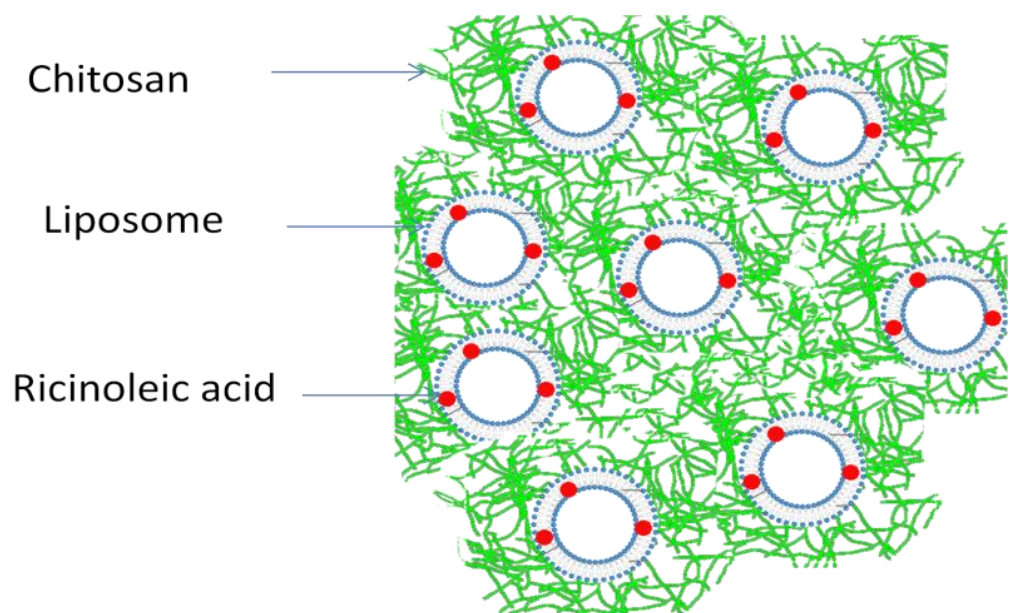

Fig. 2: The suggested approach of the microspheres production in which liposomes surrounded by chitosan chains (green lines represent chitosan chains; red spots represent fatty acid drugs; blue lines represent liposomal phospholipids).

bath. At time intervals, $1 \mathrm{~mL}$ of the released medium was taken and $1 \mathrm{~mL}$ methanol was added to lyse the liposomes and $2 \mathrm{~mL}$ acetone was added to dissolve RA. The $4 \mathrm{~mL}$ mixture was filtered through $0.2 \mu \mathrm{m}$ membrane and the absorbance readings of the supernatant were recorded at $222 \mathrm{~nm}$. The released amount was calculated from standard calibration curve.

\section{Encapsulation efficiency}

The encapsulation efficiency was defined as the measurement of the remaining content of the core material which is encapsulated in the wall material compare to the starting core material content:

$\mathrm{EE} \%=[$ Practical loading drug $] /[$ Theoretical loading drug $] \mathrm{X} 100$

The practical loading drug was measured as mentioned above in the release study.

\section{Cytotoxicity assessment}

In general, any substance or formula that comes into contact with an open wound should be clean and liberate no chemical agent that may be toxic or have an adverse effect on healing process. Micro-culture Tetrazolium (MTT) assay is a useful technique for detecting such agents by using the yellow tetrazolium dye to measure the cell viability (Nada et al., 2011). The cytotoxicity test of the prepared samples was conducted in adaption from the ISO10993-5 standard test method, using the human skin fibroblasts (HFB4) cell line. The choice of fibroblast cell line was based on their role on producing the protein associates in extracellular matrix (ECM) synthesis and their crucial role in wound healing process. In typical procedure, cells were maintained in Dulbecco's modified eagle medium (DMEM):F12 Medium (nutrient mixture) $/ 10 \%$ fetal bovine serum (FBS) and were incubated at $37^{\circ} \mathrm{C}$ in $5 \% \mathrm{CO}_{2}$ and $95 \%$ humidity. HFB4 cells 


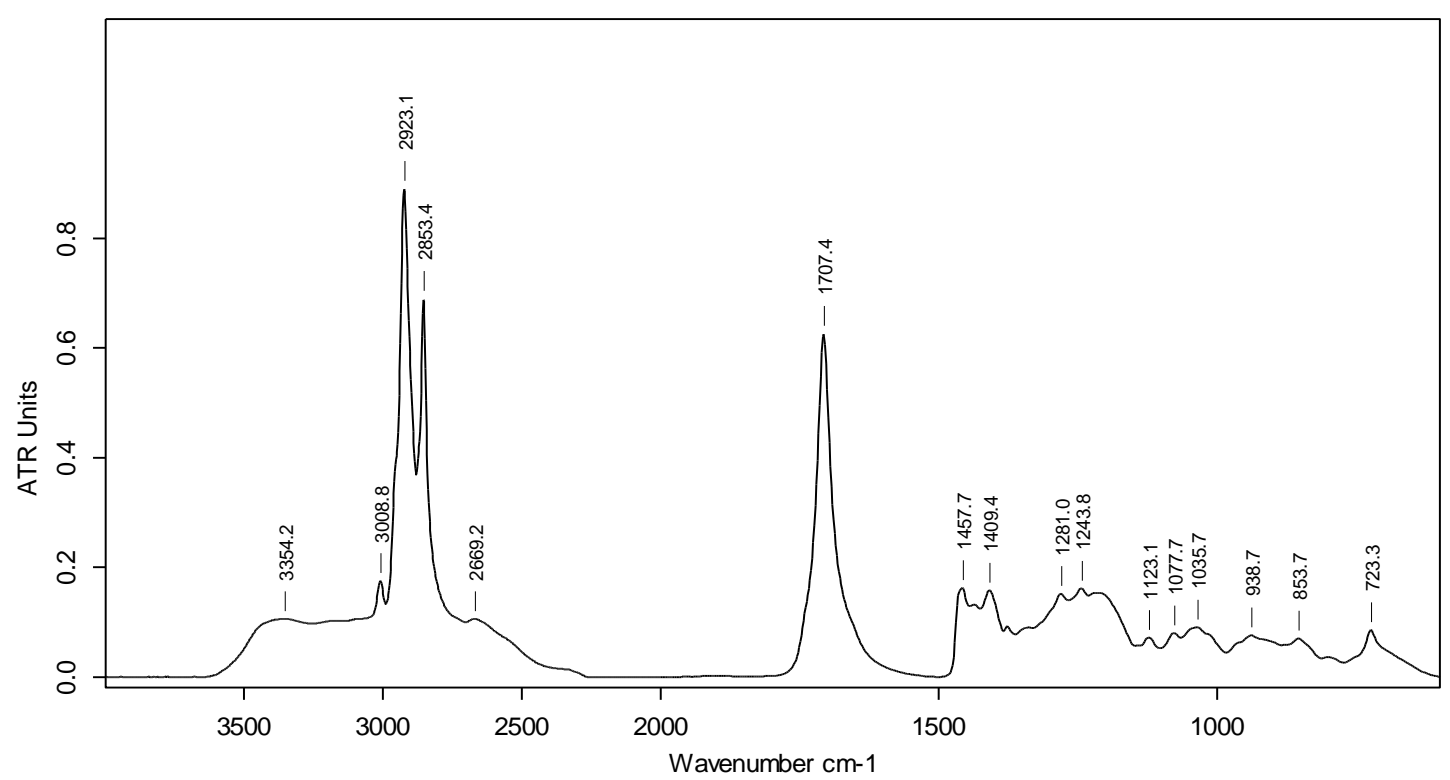

Fig. 3: FT-IR ART spectrum of ricinoleic acid.

were seeded into wells in 96-well plate and at a density of 30000 cells per well. After incubation for $48 \mathrm{hrs}$ the culture medium were replaced by extracted media of different concentrations (from 6.25 to $100 \mathrm{mg} / \mathrm{mL}$ ) of the tested compounds (each sample was tested in 3 different wells). Samples were sterilized under ultraviolet (UV) light for $20 \mathrm{~min}$ in a laminar flow before extraction while the extracted media were filter-sterilized using a $0.22 \mu \mathrm{m}$ syringe filter. Cell culture medium without additional reagents was used as the control. The plate was incubated again for $24 \mathrm{hrs}$. The amount of living cells was determined by the MTT assay.

The culture medium was aspirated and replaced by $50 \mathrm{uL}$ of MTT solution ( $5 \mathrm{mg} / \mathrm{mL}$ ). Then, the solution was incubated for $4 \mathrm{hr}$ at $37{ }^{\circ} \mathrm{C}$. The solution was aspirated and $900 \mu \mathrm{L}$ of DMSO containing $125 \mu \mathrm{L}$ of glycine buffer $(\mathrm{pH}=10)$ was added to dissolve the formazan crystals. The solution was centrifuged for $10 \mathrm{~min}$ to obtain a clear DMSO solution. The absorbance of the DMSO solutions at $570 \mathrm{~nm}$ was measured on a plate reader.

\section{Statistical analysis}

Results were expressed as a mean value with its standard deviation (mean \pm S.D.) of each sample that is repeated three times $(n=3)$. Statistical analysis was performed with student's t-test and differences were considered as significant at $\mathrm{p}$-values under 0.05 .

\section{RESULTS AND DISCUSSION}

\section{Ricinoleic acid chemical structure characterization}

Figure (3) shows the FT-IR spectra of ricinoleic acid. In the IR spectral data of ricinoleic acid a strong $\mathrm{O}-\mathrm{H}$ absorption band appears at $3354 \mathrm{~cm}^{-1}$ indicating that the hydroxyl groups of the acid remains unaffected by the alkali treatment. The strong carboxylic carbonyl absorption peak was observed at $1707 \mathrm{~cm}^{-1}$. Two strong peaks at 2923 and $2853 \mathrm{~cm}^{-1}$ indicate the alkyl part of the acid. Figure (4) shows the $\mathrm{H}^{1} \mathrm{NMR}$ spectrum of the ricinoleic acid. The chemical shifts are: $\delta 0.91 \mathrm{ppm}\left(3 \mathrm{H}, \mathrm{H}_{\mathrm{M}}\right), \delta 1.2-1.6 \mathrm{ppm}$

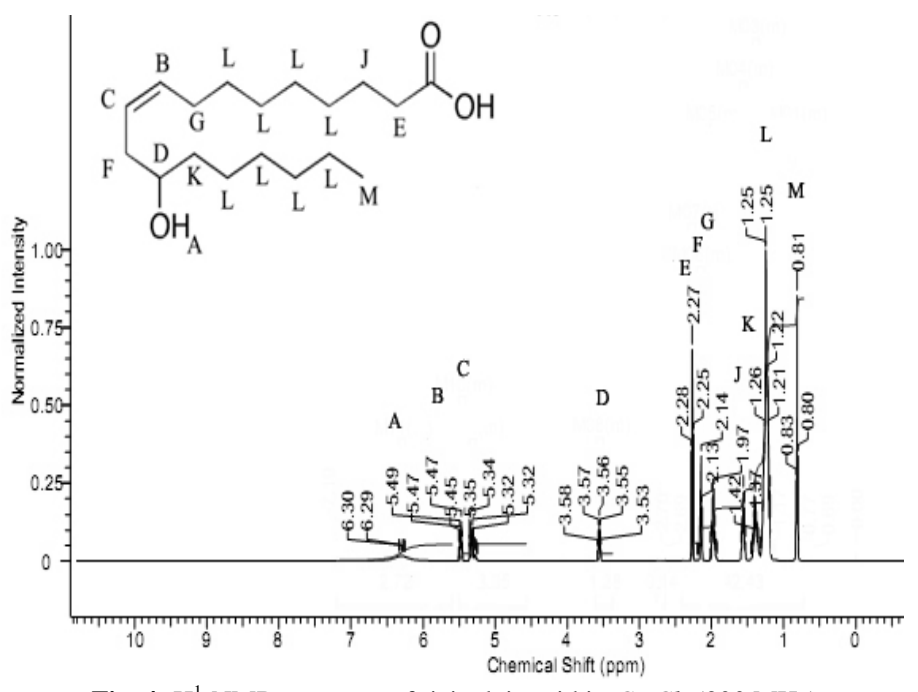

Fig. 4: $\mathrm{H}^{1}$-NMR spectrum of ricinoleic acid in $\mathrm{CDCl}_{3}(300 \mathrm{MHz})$.

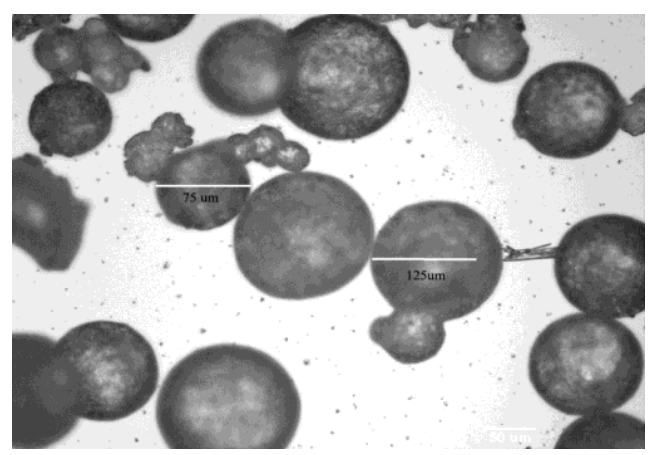

Fig. 5: Micrograph of RA-chitosan/liposomal microspheres

$\left(18 \mathrm{H}, \mathrm{H}_{\mathrm{L}}\right), \delta 1.75 \mathrm{ppm}\left(2 \mathrm{H}, \mathrm{H}_{\mathrm{K}}\right), \delta 2.1 \mathrm{ppm}\left(2 \mathrm{H}, \mathrm{H}_{\mathrm{J}}\right), \delta 2.3 \mathrm{ppm}$ $\left(2 \mathrm{H}, \mathrm{H}_{\mathrm{G}}\right), \delta 2.4 \mathrm{ppm}\left(2 \mathrm{H}, \mathrm{H}_{\mathrm{F}}\right), 3.4-3.6 \mathrm{ppm}\left(1 \mathrm{H}, \mathrm{H}_{\mathrm{C}}\right), 3.8 \mathrm{ppm}(1 \mathrm{H}$, $\left.\mathrm{H}_{\mathrm{B}}\right), 4.1 \mathrm{ppm}\left(1 \mathrm{H}, \mathrm{H}_{\mathrm{D}}\right)$ and $\delta 5.5 \mathrm{ppm}\left(1 \mathrm{H}, \mathrm{H}_{\mathrm{A}}\right)$. The characteristic hydroxyl proton at $\delta 5.5 \mathrm{ppm}$ was observed. The double bond protons are distinguished as two multiplets peaks at 3.8 and 3.4$3.6 \mathrm{ppm}$. 


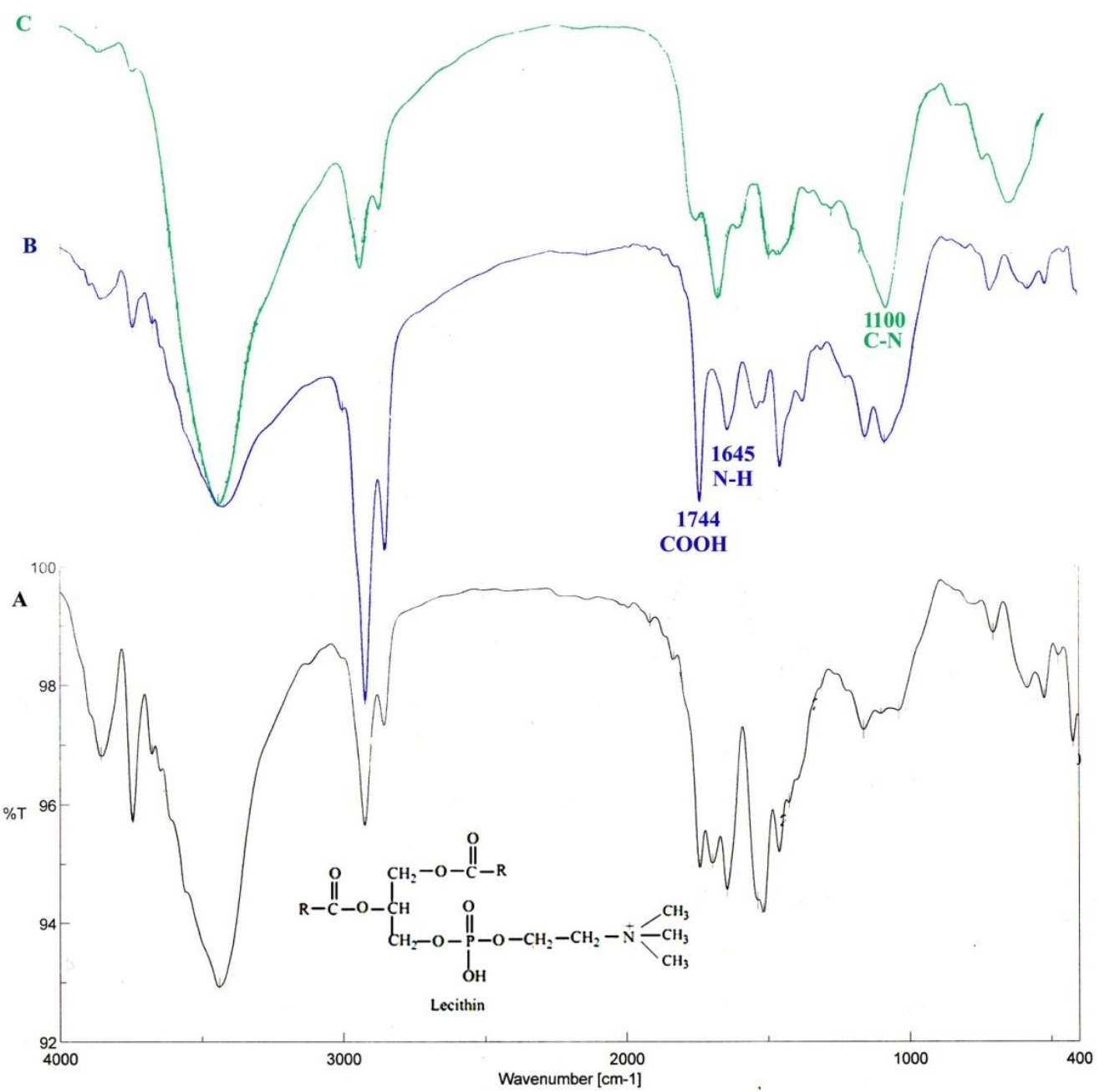

Fig. 6: IR spectra of drug-free (a); RA-liposomal (b) and RA-cross-linked-liposomal microspheres (c).
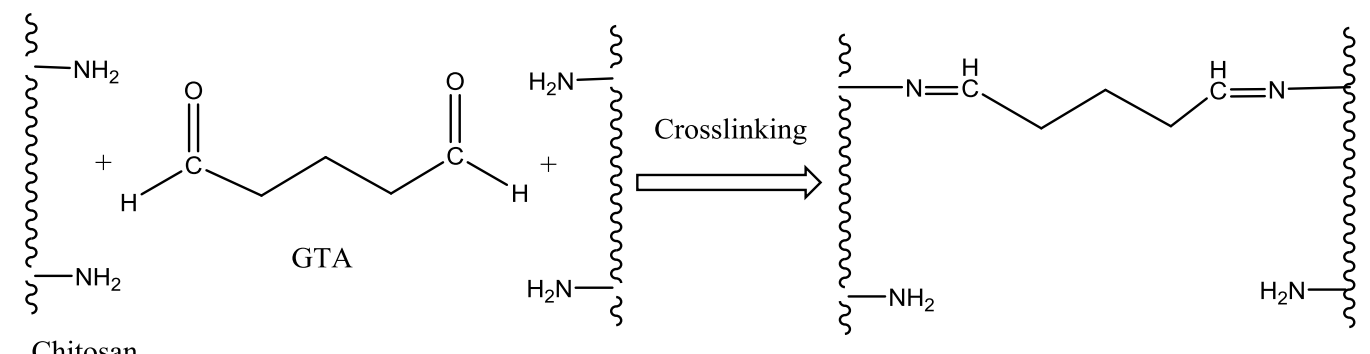

Chitosan

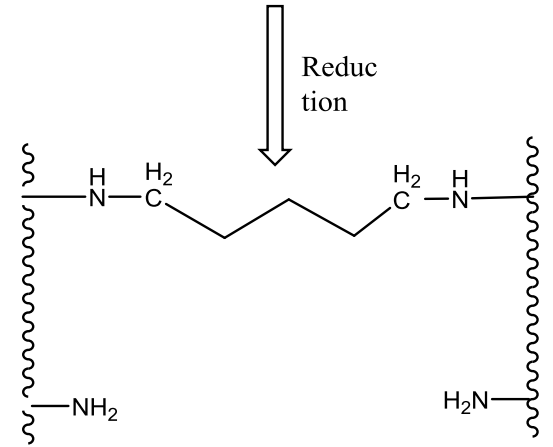

Scheme 1: Suggested mechanism of the crosslinking of the RA chitosan/liposomal microspheres With GTA. 


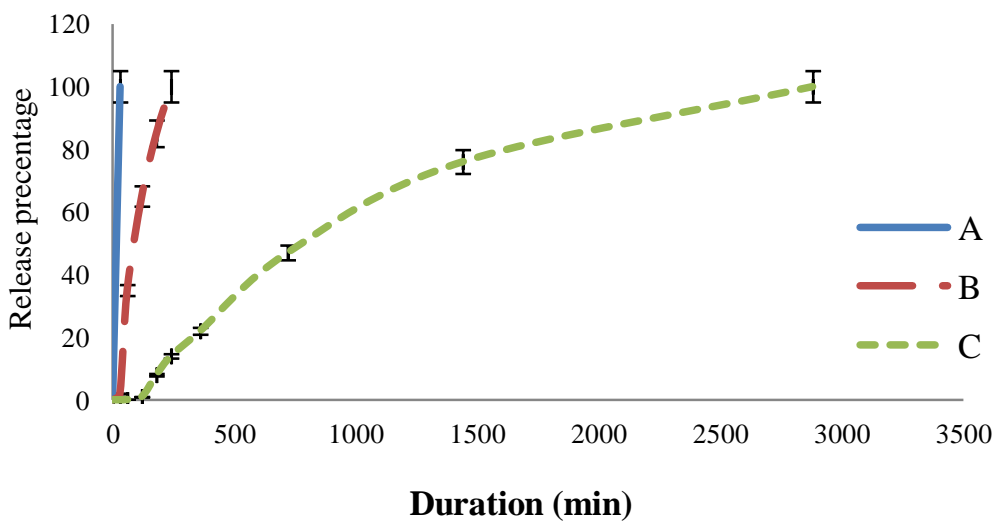

Fig. 7: Release profile of RA from RA-chitosan liposomal beads with curing time with GTA; at 0 time (A); after 2 hrs (B); after 6 hrs (c) in $0.5 \mathrm{M}$ GTA solution.

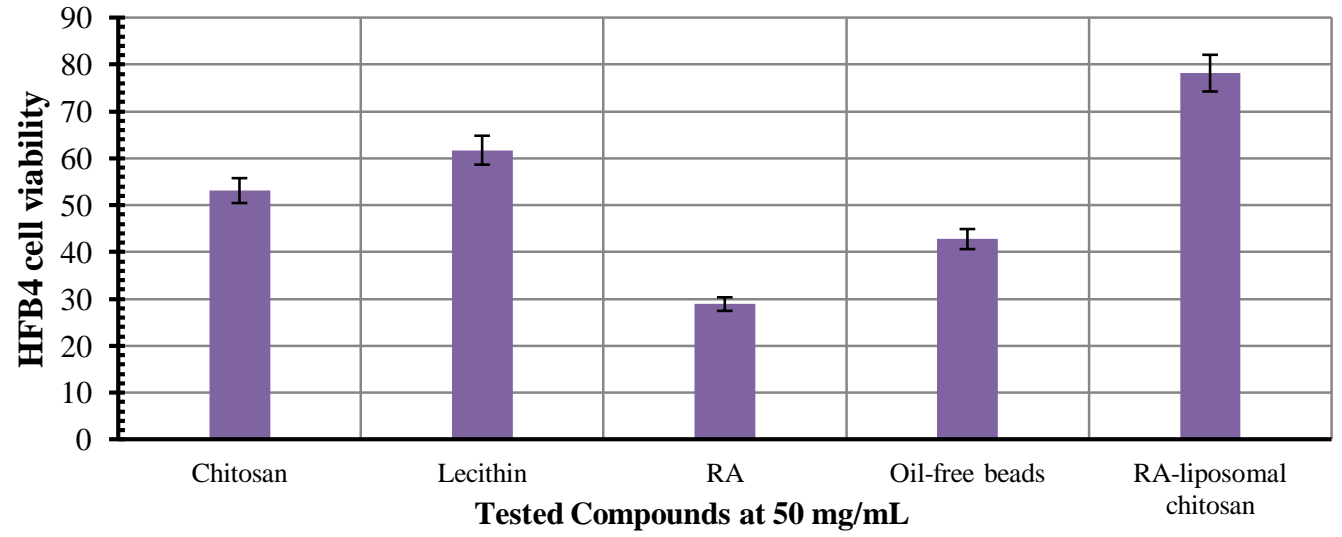

Fig. 8: The cell viability of HFB4 cells of the tested compounds at $50 \mathrm{mg} / \mathrm{mL}$.

\section{Surface morphology of RA and CLA Liposomal/Chitosan microspheres}

Figure (5) shows the morphology of the RA chitosan/ liposomal microspheres. The microspheres were quite clear in spherical shape with smooth surface. The diameter range of the microsphere was in range $150 \pm 50 \mu \mathrm{m}$.

\section{FT-IR spectra of fatty acids liposomal- chitosan microspheres}

Figure (6) shows the FT-IR spectra of drug-free (a), RAliposomes (b) and RA-cross-linked-liposomal microspheres (c).

FT-IR spectrum (a) of the liposomal chitosan (drug-free) microspheres displayed the main characteristic absorption bands of both chitosan and the phospholipid. Literally, C-H stretching at $2857 \mathrm{~cm}^{-1}$, N-H $1645 \mathrm{~cm}^{-1}$, and $\mathrm{C}-\mathrm{N} 1460 \mathrm{~cm}^{-1}$ represented the chitosan main characteristic bands. However, the phosphate group of the phospholipid band displayed at $1163 \mathrm{~cm}^{-1}$. Figure $6 \mathrm{~b}$ shows a characteristic peak of the carbonyl group of RA at $1744 \mathrm{~cm}^{-1}$. The latter is considered as a proof of the fatty acids encapsulation into the chitosan liposomal microspheres.

Figure 6c shows the characteristic peak of the chemical reaction between chitosan and GTA which corresponds the stretching of $\mathrm{C}-\mathrm{N}$ bond at $1100 \mathrm{~cm}^{-1}$. The amino groups in chitosan in spectrum $\mathrm{B}$ diminished which is indicating the formation of a Schiff's base reaction between the amino groups of the chitosan and the aldehyde groups of the GTA as described in Scheme 1.

\section{Encapsulation efficiency}

The amount of RA released from the uncross-linked beads after $15 \mathrm{~min}$ reached to $90 \%$. This phenomenon is due to the absence of any cross-linking to the microsphere matrix which leads to instance release. Therefore, the encapsulation efficiency is very high to reach $90 \%$. However, when RA-liposomal chitosan beads react with GTA at $0.5 \mathrm{M}$ for different duration, RA release profile has changed accordingly (Figure 7). Within 2 hrs of crosslinking, RA release has delayed to 4 hrs. While after $6 \mathrm{hrs}$ of cross-linking, RA release has prolonged to 2 days. GTA has formed cross-links between the amino groups of the chitosan and resulted in a slower RA release from the chitosan-liposome matrix.

\section{Cytotoxicity assessment}

Biocompatibility of the produced liposomal chitosan matrix including the RA was demonstrated by fibroblast cell viability. Material toxicity is defined as greater than $30 \%$ cell death (Nada et al., 2014). Figure (8) shows the cell viability of HFB4 cells against pure chitosan (medium molecular weight); pure lecithin; pure RA; drug-free chitosan liposomes; and RA liposomal chitosan bead. Results shown in Figure (8) reveal that all samples have passed the $30 \%$ cell viability except for the RA samples. Such adverse effect for RA on cell viability may be attributed to their surfactant characteristics associated with their 
capability to inhibit water transfer to cells and isolate cells. Add to that, RA showed significant cell death more than other for its laxative actions (fluid secretion) (Gaginella et al., 1977). Also the increase of cytotoxicity of chitosan is due to the higher amount used $(50 \mathrm{mg} / \mu \mathrm{L})$ to prepare the extraction medium. It has been reported that chitosan with different molecular weights showed significant cytotoxicity at concentration higher than $0.741 \mathrm{mg} / \mathrm{mL}$ (Huang et al., 2004).

\section{CONCLUSION}

RA was extracted from commercial castor oil and characterized via spectral analysis. RA was encapsulated into stable chitosan/liposome matrix by cross-linking with GTA. The release profile of RA has changed upon the duration time with the cross-linking with GTA. The RA chitosan-liposomal bead and its constituents were proved to be non-toxic matrix. The new chitosan/ lecithin matrix can be considered as a good approach for protecting RA from environmental degradation and presenting RA for topical applications.

\section{ACKNOWLEDGEMENTS}

This project was supported financially by the Science and Technology Development Fund (STDF), Egypt, Grant No: 4938). Authors are grateful to National Research Centre (Scopus affiliation ID: 60014618) for facilities provided. The authors have declared no conflicts of interest.

\section{REFERENCES}

Adeyeye, M. C., Jain, A. C., Ghorab, M. K. M., and Reilly, W. J. Viscoelastic evaluation of topical creams containing microcrystalline cellulose/sodium carboxymethyl cellulose as stabilizer. Am. Assoc. Pharm. Sci. PharmSciTech, 2002; 3(2), E8.

Andreuccetti, C., Carvalho, R. A., and Grosso, C. R. F. Effect of hydrophobic plasticizers on functional properties of gelatin-based films. Food Res. Int., 2009; 42(8), 1113-1121.

Aramwit, P., and Sangcakul, A. The effects of sericin cream on wound healing in rats. Biosci. Biotechnol. Biochem., 2007; 71(10), 24732477.

Bigi, a, Cojazzi, G., Panzavolta, S., Rubini, K., and Roveri, N. Mechanical and thermal properties of gelatin films at different degrees of glutaraldehyde crosslinking. J. Biomed. Mater. Res., 2001; 22, $3-8$.

Bigi, a., Cojazzi, G., Panzavolta, S., Roveri, N., and Rubini, K. Stabilization of gelatin films by crosslinking with genipin. Biomaterials, 2002; 23(24), 4827-4832.

Cao, N., Fu, Y., and He, J. Mechanical properties of gelatin films cross-linked, respectively, by ferulic acid and tannin acid. Food Hydrocoll., 2007; 21(4), 575-584.

Cheng, M., Deng, J., Yang, F., Gong, Y., Zhao, N., and Zhang, $\mathrm{X}$. Study on physical properties and nerve cell affinity of composite films from chitosan and gelatin solutions. Biomaterials, 2003; 24(17), 28712880 .

Cheng, Y., Nada, A. a., Valmikinathan, C. M., Lee, P., Liang, D., Yu, X., and Kumbar, S. G. In situ gelling polysaccharide-based hydrogel for cell and drug delivery in tissue engineering. J. Appl. Polym. Sci., 2014; 131(4), 39934.

Denkbaş, E. B., and Odabaşi, M. Chitosan microspheres and sponges: preparation and characterization. J. Appl. Polym. Sci., 2000; 76(11), 1637-1643.
Dong, Z., Wang, Q., and Du, Y. Alginate/gelatin blend films and their properties for drug controlled release. J. Memb. Sci., 2006; 280(1-2), 37-44.

Donthidi, a R., Tester, R. F., and Aidoo, K. E. Effect of lecithin and starch on alginate-encapsulated probiotic bacteria. J. Microencapsul., 2010; 27(1), 67-77.

Gaginella, T. S., Haddad, A. C., Go, V. L. W., and Phillips, S F. Cytotoxicity of ricinoleic acid (castor oil) and other intestinal secretagogues on isolated intestinal epithelial cells. J. Pharmacol. Exp. Ther., 1977; 201(1), 259-266.

Gaginella, T.S., and Philips, S. F. Ricinoleic Acid: Current View of an Ancient Oil. Dig. Dis., 1975; 20(12), 1171-1177.

Gómez-Estaca, J., López de Lacey, a., Gómez-Guillén, M. C., López-Caballero, M. E., and Montero, P. Antimicrobial Activity of Composite Edible Films Based on Fish Gelatin and Chitosan Incorporated with Clove Essential Oil. J. Aquat. Food Prod. Technol., 2009;18(1-2), 46-52.

Huang, M., Khor, E., and Lim, L. Y. Uptake and Cytotoxicity of Chitosan Molecules and Nanoparticles: Effects of Molecular Weight and Degree of Deacetylation. Pharm. Res., 2004; 21(2), 344-353.

Jenning, V., Gysler, A., Schäfer-Korting, M., and Gohla, S. H. Vitamin A loaded solid lipid nanoparticles for topical use: Occlusive properties and drug targeting to the upper skin. Eur. J. Pharm. Biopharm., 2000; 49(3), 211-218.

Kumar, R., and Katare, O. P. Lecithin organogels as a potential phospholipid-structured system for topical drug delivery: a review. AAPS PharmSciTech, 2005; 6(2), E298-E310.

Kumbar, S. G., Laurencin, C. T., and Deng, M. 2014. Natural and Synthetic Biomedical Polymers. Newnes. Availabe at http:// books.google. $\operatorname{com} /$ books? $\mathrm{hl}=$ enandlr=andid=QX58AQAAQBAJandpgis $=1$

Lee, J. S., Kim, H. W., Chung, D., and Lee, H. G. Catechinloaded calcium pectinate microparticles reinforced with liposome and hydroxypropylmethylcellulose: Optimization and in vivo antioxidant activity. Food Hydrocoll., 2009; 23(8), 2226-2233.

Levi, S., Rac, V., Manojlovi, V., Raki, V., Bugarski, B., Flock, T., Nedovi, V. Limonene encapsulation in alginate/poly (vinyl alcohol). Procedia Food Sci., 2011; 1, 1816-1820.

Lin, S. Y., and Ayres, J. W. Calcium alginate beads as core carriers of 5-aminosalicylic acid. Pharm. Res., 1992; 9(9), 1128-1131.

Matsuda, S., Iwata, H., Se, N., and Ikada, Y. Bioadhesion of gelatin films crosslinked with glutaraldehyde. J. Biomed. Mater. Res., 1999; 45(1), 20-27.

Meyer, J. D., Falk, R. F., Kelly, R. M., Shively, J. E., Withrow, S. J., Dernell, W. S., Manning, M. C. Preparation and in vitro characterization of gentamycin-impregnated biodegradable beads suitable for treatment of osteoyelitis. J. Pharm. Sci., 1998; 87(9), 1149-1154.

Miura, S., Tanaka, M., Suzuki, A., and Sato, K. Application of phospholipids extracted from bovine milk to the reconstitution of cream using butter oil. J. Am. Oil Chem. Soc., 2004; 81(1), 97-100.

Nada, A. a., Hauser, P., and Hudson, S. M. The grafting of per(2,3,6-O-allyl)- $\beta$ cyclodextrin onto derivatized cotton cellulose via thermal and atmospheric plasma techniques. Plasma Chem. Plasma Process., 2011; 31(4), 605-621.

Nada, A. A., James, R., Shelke, N. B., Harmon, M. D., Awad, H. M., Nagarale, R. K., and Kumbar, S. G. A smart methodology to fabricate electrospun chitosan nanofiber matrices for regenerative engineering applications. Polym. Adv. Technol., 2014; 25(5), 507-515.

Paolino, D., Ventura, C. A., Nisticò, S., Puglisi, G., and Fresta, M. Lecithin microemulsions for the topical administration of ketoprofen: Percutaneous adsorption through human skin and in vivo human skin tolerability. Int. J. Pharm., 2002; 244(1-2), 21-31.

Raza, K., Singh, B., Mahajan, A., Negi, P., Bhatia, A., and Katare, O. P. Design and evaluation of flexible membrane vesicles (FMVs) for enhanced topical delivery of capsaicin. J. Drug Target., 2011; 19(4), 293-302.

Sadaf, F., Saleem, R., Ahmed, M., Ahmad, S. I., and Navaid-ulZafar. Healing potential of cream containing extract of Sphaeranthus indicus on dermal wounds in Guinea pigs. J. Ethnopharmacol., 2006; 107(2), 161-163. 
Sahiner, N., and Singh, M. In situ micro/nanohydrogel synthesis from acrylamide derivates with lecithin organogel system. Polymer (Guildf)., 2007; 48(10), 2827-2834.

Salimon, J., Salih, N., and Yousif, E. Synthesis and characterization of esters derived from ricinoleic acid and evaluation of their low temperature properties. Sains Malaysiana, 2012; 41(10), 12391244.

Scartazzini, R., and Luisi, P. Organogels from lecithins. J. Phys. Chem., 1988; 92(3), 829-833.

Shchipunov, Y. a. Lecithin organogel A micellar system with unique properties. Colloids and Surfaces, 2001; 185, 541- 554.

Silva, C. M., Ribeiro, A. J., Figueiredo, M., Ferreira, D., and Veiga, F. Microencapsulation of hemoglobin in chitosan-coated alginate microspheres prepared by emulsification/internal gelation. Am. Assoc. Pharm. Sci. J., 2005; 7(4), E903-E913.

Sobral, P. J. a, Menegalli, F. C., Hubinger, M. D., and Roques, M. a. Mechanical, water vapor barrier and thermal properties of gelatinbased edible films. Food Hydrocoll., 2001; 15(4-6), 423-432.

Takahashi, M., Inafuku, K., Miyagi, T., Oku, H., Wada, K., Imura, T., and Kitamoto, D. Efficient preparation of liposomes encapsulating food materials using lecithins by a mechanochemical method. J. Oleo Sci., 2006; 56(1), 35-42.

Tanaka, A., Nagate, T., and Matsuda, H. Acceleration of wound healing by gelatin film dressings with epidermal growth factor. J. Vet. Med. Sci., 2005; 67(9), 909-913.

Urano, S., Yano, K., and Matsuo, M. Membrane-stabilizing effect of vitamin E: effect of alpha-tocopherol and its model compounds on fluidity of lecithin liposomes. Biochem. Biophys. Res. Commun., 1988; 150(1), 469-475.

Vaisman, B., Shikanov, A., and Domb, A. J. The Isolation of Ricinoleic Acid from Castor Oil by Salt-solubility-based Fractionation for the Biopharmaceutical Applications. J. Am. Oil Chem. Soc., 2007; 85(2), $169-184$.

Vaisman, B., Shikanov, A., and Domb, A. J. The isolation of ricinoleic acid from castor oil by salt-solubility-based fractionation for the biopharmaceutical applications. J. Am. Oil Chem. Soc., 2008; 85(2), 169 184.
Vanin, F. M., Sobral, P. J. a, Menegalli, F. C., Carvalho, R. a., and Habitante, a. M. Q. B. Effects of plasticizers and their concentrations on thermal and functional properties of gelatin-based films. Food Hydrocoll., 2005; 19(5), 899-907.

Vieira, C., Evangelista, S., Cirillo, R., Lippi, a, Maggi, C. a, and Manzini, S. Effect of ricinoleic acid in acute and subchronic experimental models of inflammation. Mediators Inflamm., 2000; 9(5), 223-8.

Vieira, C., Evangelista, S., Cirillo, R., Terracciano, R., Lippi, a, Maggi, C. a, and Manzini, S. Antinociceptive activity of ricinoleic acid, a capsaicin-like compound devoid of pungent properties. Eur. J. Pharmacol., 2000; 407(1-2), 109-16.

Vieira, C., Fetzer, S., Sauer, S., Evangelista, S., Averbeck, B., Kress, M., Manzini, S. Pro- and anti-inflammatory actions of ricinoleic acid: similarities and differences with capsaicin. Naunyn. Schmiedebergs. Arch. Pharmacol., 2001; 364(2), 87-95.

Vintiloiu, A., and Leroux, J.-C. Organogels and their use in drug delivery--a review. J. Control. Release, 2008; 125(3), 179-192.

$\mathrm{Xi}$, J., Guo, R., and Guo, X. Interactions of hemoglobin with lecithin liposomes. Colloid Polym. Sci., 2006; 284(10), 1139-1145.

Yakimets, I., Wellner, N., Smith, A. C., Wilson, R. H., Farhat, I., and Mitchell, J. Mechanical properties with respect to water content of gelatin films in glassy state. Polymer (Guildf)., 2005; 46(26), $12577-$ 12585 .

Zhou, H., Yue, Y., Liu, G., Li, Y., Zhang, J., Gong, Q., Duan, M. Preparation and Characterization of a Lecithin Nanoemulsion as a Topical Delivery System. Nanoscale Res. Lett., 2010; 5(1), 224-230.

\section{How to cite this article:}

Rihab Abd EL Azeem, Ahmed A. Nada, Ahmed S. Montaser. Chitosan Liposomal microspheres for Ricinoleic acid Encapsulation. J App Pharm Sci, 2015; 5 (11): 055-062. 